\title{
Analysis on Features of Domestic Feminist Translation Theory and Limitation to Translation Practice
}

\author{
Yongqiang Xia \\ Sichuan University of Arts and Science, Dazhou, 635000, China
}

Keywords: Domestic feminism, Translation theory, Translation limitation

\begin{abstract}
In the later half of the $20^{\text {th }}$ century, women put their attention on the integration of translation and feminism based on the tide of "cultural turn”. Since then, sex factor becomes an important content in translation. Feminist translation was also generated in this process. In the earliest, the feminist translation theory was generated in Canada. This is a translation school with distinct characteristics. The feature of the school of feminist translation is to internally break traditional translation theory, set up anti-binary opposition mode of thinking to finish translation, really highlight translation of female identity position, and realize language and political equality of women.
\end{abstract}

\section{Introduction}

The feminist translation theory was continuously improved in its generation and development process, enriching the horizon of translators, enriching and innovating the knowledge structure of contemporary literary translation theory, and opening a new path for development of translation. At the same time, the formation of feminist translation theory becomes a positive dynamic factor of the ideological trend of feminism. In China, fewer researches are made on feminist translation theory. In this paper, the author discussed relevant features of domestic feminist translation theory and its limitations in practical work.

\section{Combination of Feminism with Translation}

Femininity reflected in the translation process is always a historical metaphor effect. In traditional translation theory, translation is usually treated as a marriage. The relationship between the original author and original work \& the translator is similar to a marriage between a man and a woman in traditional society. Translation is beautiful but disloyal or loyal but not beautiful. It is very difficult for translators to really balance the relationship between the two items.

\section{Causes for sex and feminism}

Generation of feminism should trace back to appearance of human's sex difference. The work of sex itself has no any affective characteristics or class characteristics. Humans are living in this world with only men and women. This is natural selection of human evolution. Such sex difference will be reflected in real life, and correspond to social culture value and gender consciousness. Sex difference will have dissimilation. Affected by traditional patriarchy, sex has stiff prejudice against identity and integrated quality between men and women. Moreover, hierarchy is forcedly generated. More seriously, it even has essential difference, resulting in huge social difference between men and women. Moreover, such hierarchy wants to make people realize inequality between men and women through such difference. Physiological difference is used to interpret phenomenon of inequality between men and women. At the same time, women were warned that women must accept such difference.

Relevant researchers and scholars have their own opinions on unfair phenomena for women behind sex. With continuous social development, obvious achievements are realized in sex researches. Relevant researchers and scholars even challenged sex unfairness left in social and historical culture. Among these researchers and scholars, Simone de Beauvoir, a famous French writer, used to propose the following views: “the main reason for human's becoming women is national formation. It is 
unnecessary for victory or qualitative psychology". The word of "women" was appeared in the course of human cultural development, and formed under ruling by men's society. In the earliest, the word of "feminism" was sourced from the word of "women" in French. Subsequently, it appeared in English. Eventually, it becomes an important sign in female liberation movement.

\section{Sex issues existing in translation}

Merely, translation cannot be inevitably correlated with sex. However, reaction takes place between translation and sex when translation is under the overall environment of feminist ideological trend. Moreover, sexual identity is rooted in translated text.

Primary path of women into cultural subject position

Since the Middle Ages, men were always leading roles in social and cultural life. Women were always in bottom or on edges of society. Literature was also a special field for men. However, women were always rejected on the edges. Only in religious references, women can participate in literature or be engaged in works related to literature. Religion is served as a political tool or means used to restrain human's thought. For women, even related translation works were reflected in religion. This phenomenon will stimulate women to have the thought of rebellion against imprisonment. Just under such cognition, women began to be unsatisfied with their social identity and further require improving their position $n$ religious references.

Similarities between translation and women's position

In traditional social environment, men were passively positioned onto active, masculine and independent images; while women were positioned on passive, feminine and dependent images. Such relationship between men and women in sex and position was followed in the history, and continuously inherited in the literary world. In traditional literary world, translation is also denied as a "medium". Even Guo Moruo (a famous writer and poet in China) called translation as a "medium". Certain special correlation exists between feminism and translation. To this end, feminists never kept silence as before, and they decided to finish feminist research on translation and to realize transformation of their identity and position through such behavior, so as to enrich and complete feminist translation theory.

\section{Analysis on Limitation of Domestic Feminist Translation Practice}

The feature of strong rebellion against traditional patriarchy exists in the feminist translation theory and view, which becomes an important weapon for women to obtain the right of expression. However, feminist translation theory has various categories. Many views are even too radical, resulting in strong rebellion in political expression. To some extent, it already surpasses the essence of feminist translation theory. Thus, it inevitably causes the limitation of feminist translation theory. With continuous enrichment and development of feminist translation theory, translation theory is changed, and different schools are formed on this basis. The school of feminist translation theory follows respective views, and applied many theories and practical styles of writing loyal to women into their theories, further promoting surging of various schools. In the development course of feminist translation theory, it is incomplete for generation and development of various schools. In this process, these schools also exposed their limitations.

\section{Consciousness of self- overturn}

The school of self- overturn consciousness mainly refers to feminist translation schools criticized by Liu Huiying, a female reviewer in China. Based on relevant features of this school, Liu Huiying adopted the following three professional terms to describe the school of self- overturn consciousness:

Firstly, opportunism: this feature of overturn consciousness is based on denial against single and absolute features of original text, and finishes criticism and rebellion against traditional culture ruled by paternity, so as to realize improvement to female identity and social status. Based on the standpoint of female, this school finishes overturn and rewriting of original train of thought. In the translation process, they paid more attention to the translator's participation process in the original cooperation plan, resulting in their excessive persistence in translation belief and thus causing extremism. Besides, it is a kind of translation based on the original text due to the attribute of 
translation. Therefore, we should show respect for the original text, and truly reflect the purpose of original text. To this end, Liu Huiying classified this category of self-contradictory statements into opportunism.

Secondly, hypocrisy: such feminism adopts double standards for translation theory and relevant translation criticism. To this end, Liu Huiying pointed out some feminists and subverters based on such circumstance, who also had differences in political prejudice and ideology. In this process, however, they objectively neglected aggressiveness and tendency of violence. Through above analysis, we can find that violence of ideology reflected in translators among these feminists is more brutal than violence reflected in traditional men in the original text.

Thirdly, theoretical limitation: feminist translation theory used for reference and absorbed the features of theories related to deconstructivism and post-colonialism, and expressed the theories in feminism through the pattern of deconstructivism. Liu Huiying used to discuss multi-element and openness features of meaning while talking about deconstructivism-related views. She thought that feminism was aimed at the contents in the parts of gender consciousness and space basis for its influence in the original text. This ideology itself has no inevitability.

\section{Elitism}

In the internal system of feminist translation theory, there is a translation theory practice called "elitism". As an important carrier of human's ideology, language has the functions of exchange and cultural communication. To this end, language translation itself should have the function of easy comprehension and exchange. If translators neglect this angle and view, they cannot form translation in a complete sense. It is a kind of killing toward the connotation of original text by only improving women's social status only from the angle of feminism and creating more difficult contents of style and literary form in translated text. Moreover, it cannot achieve the effect of language cultural exchange. At last, an excellent piece of work may be placed in an awkward position. French feminist experimenters, writers and practitioners are representatives of this category. Their works were not created to cater for the public. Instead, their purpose is locked among new feminists under good education. Language artistic attainments are very high for these works. However, these artistic works cannot really meet the taste of common readers. Therefore, their works cannot be called good works in a real sense. Rita criticized experiment, writing and practice of French feminists. This view of criticism can be applicable to translation practice in a better way. Feminist translation theory researchers should consider readers' educational background to some extent. At the same time, they should not use the contents of too many cultural and word games in one text, or adopt many puns or metaphors, so as to allow elite women to comprehend the text.

\section{New colonialism}

The third category is mainly of Britain, France and America. It is mainly reflected in the phenomenon of new colonialism. New colonialism reflected in translation works originally began with literary translation by an American Asian-Indian scholar. This scholar is Gayatri Chakrovorty Spivak. In her literary translation, she had her unique views toward literature of the third world. She advocated phenomena of colonization appeared in literary works. The view of this colonization phenomenon is based on the theory of Spivak. Therefore, the theory of Spivak further proves political connotation of translation. Spivak pronounced that feminism existed in both developed countries and the third world. Such speech promoted more feminists to positively develop feminist literary translation about the third world. This also makes another issue under wide attention, namely translation of languages in developing countries into English. English is featured by wideness and universality. English translation can allow more people to have deep understandings of women's issues in the third world countries. However, this issue still cannot be used to definitely judge whether language colonization of developing countries is realized by developed countries. Universality of English becomes the main reason for its application. Realization of English translation also conforms to language needs of more people. In the third world feminist translation, however, another issue appeared, namely the trend of colonialism reflected by western women. They utilized their languages for English translation, and overlooked language characteristics of the original text. Spivak seriously 
criticized this trend, and strongly disagreed with the trend of "standard language" in translation, namely objection and criticism against this translation trend with a strong color of language right.

Besides language information, judgment on a piece of work also includes writing feature and skill. At the same time, it also reflects background and cultural environment of the country of the original text. In the translation process, therefore, it will not cause the appearance of new colonialism, if no detailed understanding about creation background and behavioral features of the original work. While making comments on feminist translation in literary works, Spivak said that the purpose of translated materials was to contact with readers in a better way, positively advocate feminist unity, and eliminate discrimination against female. However, principles of translation are overlooked, making translation fail to respect the original text, and making it vague for feminist differences in different regions. This kind of translation is unfavorable for correct communication of feminism. At the same time, such translation makes women in the third world unable to understand real conditions of women in western countries and other different cultures, forming non-western world colonization.

\section{Conclusion}

To sum up, the generation of feminist translation theory has its internal causes. Inevitably, feminist translation theory has its reasonable features. From generation to development, relevant researches on feminist translation theory are always made. Affected by historical factors, women are always recorded in history annals with humble images. As time goes by, however, exchange between different regions is deepened. Women's influence in religion is gradually transmitted. To some extent, this plays a positive role in promoting the rise of women's status. Translation belongs to a kind of career. More importantly, it is also an exchange tool. Through translation, human society realized cultural and thought exchange, and widely transmitted the connotation of feminist theory. In this paper, it is impossible to list numerous examples about translation practice. However, the author made a rough analysis on features of domestic feminist translation theory under current environment and relevant issues about practical limitation.

\section{References}

[1] Wang Zheng, Discussion on Development of Social Sex Science in China, Du Fangqin and Wang Xiangxian, Research on Women and Social Sex In China, Tianjin: Tianjin People’s Publishing House, 2013: 28;

[2] Xu Lai, Significance of Rewriting Feminist Translation Theory under the Name of Women for Translators' Subjectivity Research, Chinese Translators Journal, 2012: 16-17;

[3] Zhang Jinghua, Overturn of Feminism for Traditional Discussion and Its Limitation, Chinese Translators Journal, 2011, (4): 20;

[4] Run Jianhua, Sex Difference and Translation: Unscrambling Feminist Translation View, Journal of Zhejiang University of Technology, 2012, (6): 594-597;

[5] Xiang Hongmei and He Minglie, Feminist Translation Practice under Chinese Context, Journal of Hotan Teachers College, 2011: 164;

[6] Shen Yifei, Structured Women: Sex Theory of Contemporary Society, Shanghai People's Publishing House, 2005: 121 